\title{
Type of Delivery and Length of Stay in Hypertension Patients
}

\author{
Syahriana ${ }^{1,2}$, Nasrudin Andi Mappaware ${ }^{1,3}$, Yusrawati Hasibuan ${ }^{4}$, Elizawarda ${ }^{4,5} \&$ Andi Nilawati Usman ${ }^{6,7}$ \\ ${ }^{1}$ Postgraduate Program, Department of Midwifery, Hasanuddin University, Makassar, South Sulawesi, Indonesia \\ ${ }^{2}$ Regional Public Hospital of Makassar, Makassar, South Sulawesi, Indonesia \\ ${ }^{3}$ Faculty of Medicine, Indonesia Muslim University, Makassar, South Sulawesi, Indonesia \\ ${ }^{4}$ Department of Midwifery, Medan Polytechnic of Health Sciences, Medan, North Sumatera, Indonesia \\ ${ }^{5}$ Human Resource Education and Training Unit, Department of Midwifery, Medan Polytechnic of Health Sciences, \\ Medan, North Sumatera, Indonesia \\ ${ }^{6}$ Hallal Center for Public Health Research, Faculty of Public Health, Hasanuddin University, Makassar, South \\ Sulawesi, Indonesia \\ ${ }^{7}$ Faculty of Public Health, Mandala Waluya College, Kendari, Southheast Sulawesi, Indonesia \\ Correspondence: Syahriana, Postgraduate Program, Department of Midwifery, Hasanuddin University, Makassar, \\ South Sulawesi, 90245, Indonesia: Tel: 62-821-9166-4594. E-mail: syahriana789@gmail.com
}

Received: April 23, 2018 Accepted: May 11, 2018 Online Published: May 16, 2018

doi:10.5539/gjhs.v10n6p158 URL: https://doi.org/10.5539/gjhs.v10n6p158

\begin{abstract}
Introduction: The length of stay (LOS) for pregnant mothers with vaginal delivery is different from that of caesarean delivery. Hypertension during pregnancy may be an indication to conduct caesarean delivery that affects length of stay in hospitals.

Material and Methods: The total collected samples were 108 pregnant mothers and they were divided into 2 groups, 54 pregnant mothers with normal blood pressure and 54 pregnant mothers with hypertension. Maternal characteristics, routine hematology, blood pressure (BP) status, type of delivery and length of stay were analyzed.

Results: Type of delivery, maternal age, height, weight, body mass index (BMI), systolic blood pressure, diastolic blood pressure, length of stay, and routine hematologic profile except leukocytes showed statistically significant correlations with hypertension for the total 108 pregnant mothers. Pregnant mothers with caesarean delivery due to pregnancy induced hypertension $(\mathrm{PIH})$ was threefold than those of normal blood pressure $(95 \%$ confidence interval, 1.343-6.563). Statistical analyses indicated significant correlations between type of delivery and length of stay for pregnant mothers with hypertension after delivery $(p$-value $=0.000)$.

Conclusion: On average, pregnant mothers who had hypertension with caesarean delivery spent at least 49-72 hours in the hospital after delivery. Indeed, the Royal College of Obstetricians and Gynecologists recommended that pregnant mothers with vaginal delivery should stay in a hospital for 1 or 2 days and those with caesarean section were suggested to stay 3 or 4 days after delivery. However, some pregnant mothers in this study spent shorter time to stay at the hospital after delivery. Therefore, it is suggested for pregnant mothers to stay at a hospital in a more sufficient period of time after delivery to give an adequate time for physicians to classify, to diagnose, or to treat complications after delivery.
\end{abstract}

Keywords: pregnancy induced hypertension, type of delivery, length of stay

\section{Introduction}

Pregnancy induced hypertension is a complication that contributes significantly to maternal and perinatal morbidity and mortality (Uzan et al., 2011; MacDonald-Wallis et al., 2012; Kazemian et al., 2014; Kattah \& Garovic, 2014; Mccarthy et al., 2015). Pregnancy induced hypertension, preeclampsia and complications occur at gestational age more than 20 weeks with maternal blood pressure at $\geq 140 / 90 \mathrm{mmHg}$ ( American College of Obstetricians and Gynecologists, 2013; Kattach \& Garovic, 2014; Melamed et al., 2014; Magee et al., 2016; Zhang et al., 2017). Preeclampsia and eclampsia contribute to maternal death for every 3 minutes worldwide (Mammaro et al., 2009; Meshram et al., 2014). Pregnancy induced hypertension (PIH) is one of the most common pregnancy complications (Durst et al., 2016) that calls for consideration to conduct a certain type of delivery 
(Haroush et al., 2005). Fetal distress caused by preeclampsia and eclampsia requires doctors physicians to perform cesarean section (Alanis et al., 2008). Length of stay after delivery at a health facility is vary among pregnant mothers (Campbell et al., 2016). Some pregnant mothers spend either shorter time or longer time compared with the actual needs. Specifically, length of stay (LOS) in a shorter period of time leads to insufficient time for physicians to detect, to diagnose, or treat complications of delivery that will in turn increase the possibility of morbidity and mortality (MD et al., 2016; Plough et al., 2017). Length of stay at a hospital for pregnant mothers with vaginal delivery is different from that of caesarean section (SC), hypertension in pregnancy may be an indication to conduct caesarean section that affects length of stay in hospitals. Therefore, this study aims to determine correlations between type of delivery and length of stay in pregnant mothers with PIH and to compare length of stay in the hospital between pregnant mothers with vaginal delivery and those with caesarean section with PIH.

\section{Materials and Methods}

\subsection{Study Design and Setting}

A prospective cross-sectional study was conducted at the Sitti Khadijah I Mother and Child Hospital Makassar, South Sulawesi, Indonesia during June until December 2017 . The total 108 samples of pregnant mothers were collected in the study which divided into two groups, 54 pregnant mothers who gave birth with hypertension and 54 pregnant mothers who gave birth with normal tension. Purposive sampling technique was used in accordance with the inclusion and exclusion criteria.

\subsection{Variables and Data Collection}

Data of samples were screened by medical officers for enrollment with maternal inclusion criteria both with hypertension and normal tension together with independent variables that include age, duration of stay, type of delivery, systolic blood pressure, diastolic blood pressure, body mass index (BMI), and routine hematology. The exclusion criteria in this study were mothers who had multiple gestation, history of heart disease, diabetes and renal disease.

\subsection{Ethical Considerations}

This study received ethical clearance from the Research and Ethics Committee, Faculty of Medicine of Hasanuddin University and was registered in 1073/H4.8.4.5.31/PP36-KOMETIK/2017.

\subsection{Data Processing and Analysis}

All collected data were encoded, and then they were entered and analyzed. We performed the statistical analyses by comparing maternal characteristics with blood pressure status which presented as mean \pm standard deviation and frequencies for categorical variables, correlations between type of delivery with blood pressure status, and correlations between type of delivery and length of stay in hypertension patients. The variables were compared by using chi-square test, T-test and Mann-Whitney test.

\section{Results}

\subsection{Socio-Demographic, Maternal Anthopometric Profile, and Routine Hematologic}

In this study, maternal characteristic data with the total 108 mothers showed that type of delivery, maternal age, height, weight, BMI, systolic blood pressure (BP), diastolic blood pressure (BP), length of stay, and routine hematologic profile except leukocytes showed statistically significant correlations with maternal hypertension. Level of education, employment status, gravidity and gestational age showed no statistically significant differences between the two groups. 
Table 1. Comparison of socio-demographic and anthopometric profile

\begin{tabular}{|c|c|c|c|}
\hline Variable & $\begin{array}{l}\text { Normal Tension } \\
\text { Group } \\
(\mathrm{n}=54)\end{array}$ & $\begin{array}{l}\text { PIH Group } \\
(\mathrm{n}=54)\end{array}$ & $p$-valuc \\
\hline \multicolumn{4}{|l|}{ Level of Education, $n$ (\%) } \\
\hline High & 25 & 30 & \multirow{2}{*}{0.441} \\
\hline Low & 29 & 24 & \\
\hline \multicolumn{4}{|c|}{ Status of Employment, $\mathrm{n}(\%)$} \\
\hline Employed & 29 & 26 & \multirow{2}{*}{0.700} \\
\hline Unemployed & 25 & 28 & \\
\hline \multicolumn{4}{|l|}{ Gravidity, n (\%) } \\
\hline Primiparous & 20 & 22 & \multirow{2}{*}{0.844} \\
\hline Multiparous & 34 & 32 & \\
\hline Age $($ mean \pm SD) & $28.87(1.2)$ & $32.04(5.7)$ & 0.007 \\
\hline Height (mean \pm SD) & $153.87(5.9)$ & $156.31(5.6)$ & 0.030 \\
\hline Weight (mean \pm SD) & $61.89(1.5)$ & $73.52(1.4)$ & 0.000 \\
\hline $\mathrm{BMI}($ mean $\pm \mathrm{SD})$ & $26.22(3.7)$ & $29.97(5.2)$ & 0.000 \\
\hline $\mathrm{GA}($ mean $\pm \mathrm{SD})$ & $38.44(1.7)$ & $38.06(2.0)$ & 0.088 \\
\hline Systolic BP $($ mean \pm SD) & $114.81(9.1)$ & $156.48(18.5)$ & 0.000 \\
\hline Diastolic BP $($ mean \pm SD $)$ & $74.48(6.5)$ & $101.67(11.3)$ & 0.000 \\
\hline LOS $($ mean \pm SD) & $1.94(1.0)$ & $2.44(1.0)$ & 0.019 \\
\hline \multicolumn{4}{|c|}{ Routine Hematology $($ mean \pm SD) } \\
\hline Hemoglobin & $10.95(1.5)$ & $11.51(1.4)$ & 0.050 \\
\hline Leukocytes & $10.73(2.6)$ & $11.65(3.5)$ & 0.124 \\
\hline Erythrocytes & $4.13(0.9)$ & $4.35(0.5)$ & 0.000 \\
\hline Hematocrit & $31.58(4.0)$ & $35.55(4.4)$ & 0.000 \\
\hline Platelets & $294.41(67.3)$ & $247.46(64.2)$ & 0.000 \\
\hline Glucose & $95.81(14.1)$ & 103.81 & 0.007 \\
\hline
\end{tabular}

\subsection{Type Of Delivery}

Table 2 shows that hypertension significantly affects the type of delivery ( $p$-value $=0.011$ ). Pregnant mothers with caesarean delivery due to pregnancy induced hypertension (PIH) was threefold than those of normal blood pressure (95\% confidence interval, 1.343-6.563).

Table 2. Types of delivery with different blood pressures

\begin{tabular}{lllll}
\hline Delivery & $\begin{array}{l}\text { Normal Tension Group } \\
(\mathbf{n}=\mathbf{5 4})\end{array}$ & $\begin{array}{l}\text { PIH Group } \\
(\mathbf{n}=\mathbf{5 4})\end{array}$ & OR (95\% CI) & $\boldsymbol{p}$-value \\
\hline Vaginal & 30 & 16 & 2.969 & 0.011 \\
Caesarean & 24 & 38 & $(1.343-6.563)$ & \\
\hline
\end{tabular}

\subsection{Length of Stay: Correlation And Association}

The percentage of normal blood pressure with vaginal delivery was higher than that of caesarean delivery of $55.6 \%$ with LOS ranging from $24-47$ hours (56.7\%) for vaginal and 48-72 hours (54.2\%) for cesarean. The percentage of 
pregnant mothers who had hypertension with cesarean delivery was higher than that of vaginal delivery $(70.4 \%)$ with the length of stay (LOS) ranging from 48 to 72 hours $(50 \%)$, whereas normal delivery was $<24$ hours $(50 \%)$. These data showed that there were correlations between type of delivery and blood pressure status with length of stay in the hospital.

Table 3. Correlations between types of delivery and lengths of stay by four categories

\begin{tabular}{|c|c|c|c|c|c|c|}
\hline \multirow[b]{2}{*}{ Category } & \multirow{2}{*}{$\begin{array}{l}\text { Persentage } \\
\text { woman by } \\
\text { category }\end{array}$} & \multicolumn{4}{|c|}{ Leght Of Stay } & \multirow[b]{2}{*}{ P Value } \\
\hline & & $\begin{array}{l}<24 \mathrm{~h} \\
\text { Count (\%) }\end{array}$ & $\begin{array}{l}\text { 24-47 h } \\
\text { Count (\%) }\end{array}$ & $\begin{array}{l}\text { 48-72 h } \\
\text { Count (\%) }\end{array}$ & $\begin{array}{l}>72 \mathrm{~h} \\
\text { Count (\%) }\end{array}$ & \\
\hline Normal Tension + Vaginal Delivery & $55.6 \%$ & $6(20 \%)$ & $17(56.7 \%)$ & $6(20 \%)$ & $1(3.3 \%)$ & \multirow{2}{*}{0.000} \\
\hline Normal Tension + Secarean & $44.4 \%$ & $0(0 \%)$ & $2(8.3 \%)$ & $13(54.2 \%)$ & $9(37.5 \%)$ & \\
\hline PIH + Vaginal Delivery & $29.6 \%$ & $8(50 \%)$ & $5(3.2 \%)$ & $3(18.8 \%)$ & $0(0 \%)$ & \multirow{2}{*}{0.000} \\
\hline PIH + secarean & $70.4 \%$ & $0(0 \%)$ & $13(34.2 \%)$ & $19(50 \%)$ & $6(15.8 \%)$ & \\
\hline
\end{tabular}

\section{Discuccion}

Our findings indicated that the average length of stay in the hospital for mothers who had normal blood pressure with vaginal delivery was $24-47 \mathrm{~h}$. This is considerably longer than those with hypertension who have shorter treatment $(<24 \mathrm{~h}$ ) with a proportion of $55.6 \%$ versus $29.6 \%$. However, length of stay was statistically predicted longer for pregnant mothers who underwent caesarean section (NICE, 2011). Referring to risk factors, there are differences in terms of age, height, weight, body mass index of pregnant mothers. Blood pressure status (diastolic blood pressure and systolic blood pressure) also affect both groups and routine hematology profiles were different for both groups except leukocytes. Pregnant women with hypertension had the average age of 32.02 years old with the body mass index of 29.97, whereas pregnant women with normal blood pressure had the average age of 28.87 years old with the body mass index of 26.22. Overweight or obesity is a risk factor for the occurrence of preeclampsia (Sohlberg et al., 2009; Knight, Kurinczuk, \& Spark, 2010; Kazemian et al., 2014) and reveals an ascending pattern with the increase of BMI (Reyes et al., 2012; Bilano et al., 2014; Gudnadóttir et al., 2016; Li et al., 2016). In terms of maternal age, mothers within the range of 30-34 years old are 2 times more likely experience preeclampsia (Choudhury et al., 2014; Chan et al., 2015). Our findings showed that women with PIH treated by caesarean delivery up to threefold (Table 2). In this study, most pregnant mothers with hypertension had caesarean delivery with the length of stay at 48-72 hours. This is in line with pregnant mothers who have preeclampsia and eclampsia in which they should be treated with caesarean delivery (NICE, 2010; NICE, 2011; Mylonas and Friese, 2015). with the length of stay is 48-72 hours (Moroy et al., 2007), as recommended by the Royal College of Obstetricians and Gynaecologists that pregnant mothers with vaginal delivery should spend 1 or 2 days at hospitals and those with caesarean section ought to spend 3 or 4 days at hospitals (NICE, 2011). Although some pregnant women in this study with hypertension treated by vaginal delivery had shorter time to stay in hospitals with the average of length of stay was $<24 \mathrm{~h}$, this could lead to potential hemorrhage (WHO, 2013), since the first 24 hours of postpartum is the highest risk period for the mother and newborn. This study bear some limitations that include samples were collected in small number.

\section{Conclusion}

This study showed that women with PIH mostly gave birth to caesarean section with the average length of stay was 48-72 hours. This is in accordance with the recommendations of NICE that pregnant mothers with hypertension complications such as preeclampsia and eclampsia should be treated with caesarean section. Although pregnant mothers with caesarean section should stay for 48-72 hours after delivery as stated in the recommendations, some pregnant mothers in this study spent shorter time to stay at the hospital after delivery that could lead hemorrhage. Therefore, it is suggested for pregnant mothers to stay at a hospital in a more sufficient period of time after delivery to give an adequate time for physicians to classify, to diagnose, or to treat complications.

\section{Acknowledgements}

The authors express our sincere thanks to all the participants in this study. The authors also thanks director and staff of the Sitti Khadijah 1 Makassar Mother and Child Hospital for their support and assistance. 


\section{Competing Interests Statement}

The authors declare that there are no competing or potential conflicts of interest.

\section{References}

Alanis, M. C., Robinson, C. J., Hulsey, T. C., Ebeling, M., \& Johnson, D. D. (2008). Early-onset severe preeclampsia: induction of labor vs elective cesarean delivery and neonatal outcomes. American Journal of Obstetrics \& Gynecology, 199(3), 262-e1. https://doi.org/10.1016/j.ajog.2008.06.076

American College of Obstetricians and Gynecologists. (2013). Hypertension in pregnancy. Report of the American College of Obstetricians and Gynecologists' task force on hypertension in pregnancy. Obstetrics and gynecology, 122(5), 1122. https://doi.org/10.1097/01.AOG.0000437382.03963.88

Ben - Haroush, A., Yogev, Y., Glickman, H., Kaplan, B., Hod, M., \& Bar, J. (2005). Mode of delivery in pregnant women with hypertensive disorders and unfavorable cervix following induction of labor with vaginal application of prostaglandin E2. Acta obstetricia et gynecologica Scandinavica, 84(7), 665-671. https://doi.org/10.1111/j.0001-6349.2005.00681.x

Campbell, O. M., Cegolon, L., Macleod, D., \& Benova, L. (2016). Length of stay after childbirth in 92 countries and associated factors in 30 low-and middle-income countries: compilation of reported data and a cross-sectional analysis from nationally representative surveys. PLoS medicine, 13(3), e1001972. https://doi.org/10.1371/journal.pmed.1001972

Chan, T. F., Tung, Y. C., Wang, S. H., Lee, C. H., Lin, C. L., \& Lu, P. Y. (2015). Trends in the incidence of pre-eclampsia and eclampsia in Taiwan between 1998 and 2010. Taiwanese Journal of Obstetrics and Gynecology, 54(3), 270-274. https://doi.org/10.1016/j.tjog.2013.06.021

Choudhury, K. N., Mainuddin, A. K. M., Wahiduzzaman, M., \& Islam, S. M. S. (2014). Serum lipid profile and its association with hypertension in Bangladesh. Vascular health and risk management, 10, 327. https://doi.org/10.2147/VHRM.S61019

Durst, J. K., Subramaniam, A., Tang, Y., Szychowski, J. M., Campbell, S. B., Biggio, J. R., \& Harper, L. M. (2017). Mode of delivery in nulliparous women with gestational hypertension undergoing early term induction of labor. The Journal of Maternal-Fetal \& Neonatal Medicine, 30(19), 2291-2296. https://doi.org/10.1080/14767058.2016.1247153

Gudnadóttir, T. A., Bateman, B. T., Hernádez-Díaz, S., Luque-Fernandez, M. A., Valdimarsdottir, U., \& Zoega, H. (2016). Body mass index, smoking and hypertensive disorders during pregnancy: a population based case-control study. PloS one, 11(3), e0152187. https://doi.org/10.1371/journal.pone.0152187

Kattah, A. G., \& Garovic, V. D. (2013). The management of hypertension in pregnancy. Advances in chronic kidney disease, 20(3), 229-239. https://doi.org/10.1053/j.ackd.2013.01.014

Kazemian, E., Sotoudeh, G., Dorosty-Motlagh, A. R., Eshraghian, M. R., \& Bagheri, M. (2014). Maternal obesity and energy intake as risk factors of pregnancy-induced hypertension among Iranian women. Journal of health, population, and nutrition, 32(3), 486. https://doi.org/10.4172/2167-0420.1000116

Knight, M., Kurinczuk, J. J., Spark, P., \& Brocklehurst, P. (2010). Extreme obesity in pregnancy in the United Kingdom. Obstetrics \& Gynecology, 115(5), 989-997. https://doi.org/10.1097/AOG.0b013e3181da8f09

Li, K., Yao, C., Yang, X., Di, X., Li, N., Dong, L., ... \& Zheng, M. (2016). Body mass index and the risk of cardiovascular and all-cause mortality among patients with hypertension: A population-based prospective cohort study among adults in Beijing, China. Journal of epidemiology, 26(12), 654-660. https://doi.org/10.2188/jea.JE20150323

Macdonald-Wallis, C., Lawlor, D. A., Fraser, A., May, M., Nelson, S. M., \& Tilling, K. (2012). Blood pressure change in normotensive, gestational hypertensive, preeclamptic, and essential hypertensive pregnancies. Hypertension, HYPERTENSIONAHA-111. https://doi.org/10.1161/HYPERTENSIONAHA.111.187039

Magee, L. A., von Dadelszen, P., Singer, J., Lee, T., Rey, E., Ross, S., ... \& Gafni, A. (2016). The CHIPS Randomized Controlled Trial (Control of Hypertension in Pregnancy Study): is severe hypertension just an elevated blood pressure?. Hypertension, HYPERTENSIONAHA-116. https://doi.org/10.1161/HYPERTENSIONAHA.116.07862

Mammaro, A. et al. (2009). Hypertensive Disorders in Pregnancy (3(1), pp. 1-5).

McCarthy, E. A., Carins, T. A., Hannigan, Y., Bardien, N., Shub, A., \& Walker, S. P. (2015). Effectiveness and 
safety of 1 vs $4 \mathrm{~h}$ blood pressure profile with clinical and laboratory assessment for the exclusion of gestational hypertension and pre-eclampsia: a retrospective study in a university affiliated maternity hospital. BMJ open, 5(11), e009492. https://doi.org/10.1136/bmjopen-2015-009492

Melamed, N., Ray, J. G., Hladunewich, M., \& Cox, B. (2014). Gestational hypertension and preeclampsia: are they the same disease?. Journal of Obstetrics and Gynaecology Canada, 36(7), 642-647. https://doi.org/10.1016/S1701-2163(15)30545-4

Meshram, D. P. et al. (2014). Maternal and foetal outcomes in Pregnancy Induced Hypertension -A hospital based study (3(4), pp. 23-26).

Moroy, P., Ustunyurt, E., Tapisiz, O. L., Tuncay, G., Aytan, H., Ustunyurt, O. B., ... \& Mollamahmutoglu, L. (2007). Factors influencing the postpartum length of hospital stay in eclamptic women. Taiwanese Journal of Obstetrics and Gynecology, 46(4), 410-413. https://doi.org/10.1016/S1028-4559(08)60012-1

Mylonas, I., \& Friese, K. (2015). Indications for and risks of elective cesarean section. Deutsches Ärzteblatt International, 112(29-30), 489. https://doi.org/10.3238/arztebl.2015.0489

National Collaborating Centre for Women's and Children's Health (UK. (2010). Hypertension in pregnancy: the management of hypertensive disorders during pregnancy. https://doi.org/10.1136/bmj.c2207

NICE. (2011). Caesarean Section Guidelines', NICE Clinical Guideline (p. 282). https://doi.org/10.1007/s00404-011-2201-6

Oberdörster, G., Castranova, V., Asgharian, B., \& Sayre, P. (2015). Inhalation exposure to carbon nanotubes (CNT) and carbon nanofibers (CNF): Methodology and dosimetry. Journal of Toxicology and Environmental Health, Part B, 18(3-4), 121-212.

Ota, E., Ganchimeg, T., Mori, R., \& Souza, J. P. (2014). Risk factors of pre-eclampsia/eclampsia and its adverse outcomes in low-and middle-income countries: a WHO secondary analysis. PloS one, 9(3), e91198. https://doi.org/10.1371/journal.pone.0091198

Plough, A. C., Galvin, G., Li, Z., Lipsitz, S. R., Alidina, S., Henrich, N. J., ... \& McDonald, R. (2017). Relationship Between Labor and Delivery Unit Management Practices and Maternal Outcomes. Obstetrics \& Gynecology, 130(2), 358-365. https://doi.org/10.1097/AOG.0000000000002128

Reyes, L. M., García, R. G., Ruiz, S. L., Camacho, P. A., Ospina, M. B., Aroca, G., ... \& López-Jaramillo, P. (2012). Risk factors for preeclampsia in women from Colombia: a case-control study. PloS one, 7(7), e41622. https://doi.org/10.1371/journal.pone.0041622

Sohlberg, S., Stephansson, O., Cnattingius, S., \& Wikström, A. K. (2012). Maternal body mass index, height, and risks of preeclampsia. American journal of hypertension, 25(1), 120-125. https://doi.org/10.1038/ajh.2011.175

Uzan, J., Carbonnel, M., Piconne, O., Asmar, R., \& Ayoubi, J. M. (2011). Pre-eclampsia: pathophysiology, diagnosis, and management. Vascular health and risk management, 7, 467. https://doi.org/10.2147/VHRM.S20181

World Health Organization [WHO]. (2013). Postnatal care of the mother and newborn 2013 (pp. 1-72). https://doi.org/978 9241506649.

Zhang, S., Wang, L., Leng, J., Liu, H., Li, W., Zhang, T., ... \& Hu, G. (2017). Hypertensive disorders of pregnancy in women with gestational diabetes mellitus on overweight status of their children. Journal of human hypertension, 31(11), 731. https://doi.org/10.1038/jhh.2017.17

\section{Copyrights}

Copyright for this article is retained by the author(s), with first publication rights granted to the journal.

This is an open-access article distributed under the terms and conditions of the Creative Commons Attribution license (http://creativecommons.org/licenses/by/4.0/). 